\title{
Agonal Respiration
}

National Cancer Institute

\section{Source}

National Cancer Institute. Agonal Respiration. NCI Thesaurus. Code C121624.

An abnormal breathing pattern originating from lower brainstem neurons and characterized by labored breaths, gasping, and, often, myoclonus and grunting. 